DOI: $10.30612 /$ re-ufgd.v4i8.6883

\title{
EMPREENDIMENTO, COMUNIDADE E TERRITÓRIO: TRÊS OBJETOS DE INCUBAÇÃO EM ECONOMIA SOLIDÁRIA
}

Employment, Community and Territory: three Objects of Incubation in a Solidar Economy

Sanyo Drummond Pires ${ }^{1}$

Recebido em 18/09/2017

Aceito em 15/12/2017

Resumo: O presente artigo se propõe a construir uma referência conceitual para as ações de incubadoras universitárias em economia solidária, a partir da diferenciação de objetos e de objetivos que essas incubadoras apresentam em relação às incubadoras tradicionais, e das diferentes formas de avaliar os resultados das ações de extensão desenvolvidas nessas incubadoras. Observa-se que diferente das incubadoras tradicionais, o desenvolvimento de empreendimentos não se configura como o objetivo principal da incubadora, mas sim o desenvolvimento de espaços comunitários e articulações territoriais que possibilitem o fomento de práticas de busca de soluções coletivas para problemas econômicos, baseados na solidariedade e gestão coletiva.

Palavras-Chave: Incubadoras Universitárias. Economia Solidária.

Abstract: This article proposes to construct a conceptual reference for the actions of university incubators in solidarity economy, from the differentiation of objects and goals that these incubators in relation of traditional incubators, and the different ways of evaluating the results of extension actions developed in these incubators. It is observed that, unlike traditional incubators, the development of entreprises is not the main objective of the incubator, but rather the development of community spaces and territorial articulations that allow the search of collective solutions for economic problems, based on the solidarity and collective management.

Key Words: University Incubators. Solidary Economy.

\section{Introdução}

Este artigo surge da experiência como coordenador da Incubadora de Tecnologias Sociais e Solidárias (ITESS) da UFGD, e da percepção da necessidade de elaboração, a partir de reflexão metodológica que fornecesse subsídios para a compreensão das ações envolvidas no processo de incubação, de um processo formalizado de organização da ITESS e dos seus fluxos de atividades e objetos de atuação. Nesse sentido, percebeu-se ser de fundamental importância, pensar essa formalização a partir dos objetivos a serem alcançados por uma incubadora voltada para a área de economia solidária. 
Esses objetivos precisam ser compreendidos a partir da inserção conflitiva que as concepções relacionadas de economia solidária possuem em relação ao meio geral que a circunda, marcada por estruturas, valores e intenções ligadas a concepções regidas por lógicas ou do capital ou da organização burocrática. Os projetos de extensão universitária em economia solidária, e dentre eles principalmente os processos de incubação, precisam então ser diferenciados dos processos de incubação tradicionais.

Consideramos que essa diferenciação precisa ter uma definição, antes de tudo, de seus objetos, para que, a partir de então, possam então se estruturar processos metodológicos e de conformação institucional necessários. Procuramos então com esse artigo, fazer uma discussão sobre esses objetos, diferenciando-os, e principalmente, desconstruindo a percepção de que o empreendimento em si seria o objetivo direto das ações de uma incubadora de economia solidária. Embora os empreendimentos sejam também objetos importantes a serem buscados, eles se caracterizariam mais como consequência de outras ações.

\section{A Economia Solidária e sua relação com a Universidade}

As experiências e reflexões que deram origem ao que hoje chamamos de economia solidária proveem de várias fontes, bem como diferentes escolas teóricas e propostas político ideológicas. Tendo como pano de fundo em comum, a busca pela maior participação nos processos institucionais e organizacionais das entidades, geração de renda e acesso a bens e serviços, e uma vivência mais saudável e prazerosa da relação com essas entidades e com as pessoas que em comum delas participam, as concepções subjacentes à economia solidária muitas vezes não se apresentam de forma organizada. Pelo contrário, o que percebemos é que concepções contraditórias aparecem articuladas entre si, gerando incompreensões ou uma percepção da impossibilidade de superar problemas, que sendo contradições conceituais, se expressam como percepção de contradições insuperáveis também na prática.

Aspectos como a determinação da organização do trabalho pelos implementos maquinais utilizados, utilização de conceitos adequados a outros contextos como a família ou a empresas capitalistas, adesão a valores compartilhados socialmente ligados ao sucesso dentro de um modo de produção capitalista (PIRES, 2017), vem se somar, como complementos externos às contradições já inerentes 
(PIRES et al., 2013) à economia solidária, aumentando ainda mais a complexidade dos problemas a serem resolvidos no âmbito conceitual, e suas consequências no processo organizativo de coletivos que desenvolvem projetos de economia solidária.

Nesse sentido, a busca pela articulação tanto dos elementos conceituais da economia solidária, quanto sua articulação com outros processos sociais, econômicos e psíquicos importantes para a compreensão dos processos internos à economia solidária demandam um tipo de esforço que precisa ser tanto qualificado dentro de uma perspectiva multiconceitual, quanto articulados com uma preocupação com sua forma de institucionalização.

A realização dessa tarefa coube em nossa sociedade principalmente à função da universidade, que, embora não esgote tal função, cabendo esta também aos atores que desenvolvem suas atividades, e às suas instituições de representação, possui papel importante na reflexão tanto sobre sua práxis quanto sobre sua situação dentro de um contexto mais geral (SILVA, 2006). Os discursos de uma autonomia de pensamento dos movimentos sociais, e em especial o da economia solidária, se caracterizam, além de um risco, devido às dificuldades inerentes à atividade de reflexão dos movimentos sociais contestatórios (CHAUI, 1996), um ato de autoexclusão (PIRES, 2005).

No entanto, embora caiba à universidade essa articulação de conceitos, Calbino e Paula (2013) encontram, também no ambiente acadêmico, uma produção que, embora crescente, apresenta uma grande variação nas formas de conceber e nomear os processos relacionados à economia solidária, com uma produção que se dá de forma muito descontínua, sendo que a maior parte da produção se dá por meio de pesquisadores que não mantem publicações constantes sobre o tema e dispersos em diferentes periódicos de diversas áreas temáticas, geralmente com baixa avaliação.

Além disso, a produção teórica se mostra concentrada em estudos de casos, principalmente de empreendimentos específicos que nos mostra uma concentração do processo de compreensão da economia solidária na noção de empreendimento, tanto no sentido de pensar a economia solidária a partir desse nível de sua ocorrência, quanto no desenvolvimento e implementação de métodos de pesquisa sobre o tema, havendo pouca articulação da produção com processos mais complexos, envolvendo articulações de diferentes metodologias. (OLIVEIRA e ZANIN, 
2011; CALBINO e PAULA, 2013; PINHEIRO, 2016).

Apesar dessa crescente participação na produção de pesquisas e de estudos em programas de pós-graduação, a principal relação da universidade com a economia solidária se dá por meio não da pesquisa, mas das ações de extensão. Essa se encontra, da mesma forma que na pesquisa, em projetos com concepções e objetos difusos, porém de forma uma pouco mais institucionalizada, ocorrendo principalmente por meio das incubadoras de economia solidária, ou das incubadoras de tecnologias sociais. Essas, criadas a partir do modelo de incubadoras tecnológicas tradicionais, tiveram que construir todo um arcabouço conceptual do processo e dos objetivos de incubação para adequar sua ação aos processos e objetivos da economia solidária, e a principal diferença, nesse caso, foi a substituição da noção de tecnologia orientada para a inovação como um instrumento de competitividade pela noção de tecnologia social, que busca para repensar de forma crítica, aspectos relacionados tanto à gestão quanto à predeterminação da organização do trabalho por aparatos técnicos, tecnológicos e gerenciais, de forma a buscar superar, o que nesses aparatos existem em função de sustentar processos de dominação e exploração dos trabalhadores, (DUBEUX, 2007).

A noção de tecnologia social surge para lidar com uso da tecnologia como instrumento de assujeitamento e exploração, e procura estruturar formas de desenvolvimento e utilização de tecnologias que possibilitem a maior autonomia e capacidade de resolução de problemas específicos das pessoas e comunidades, principalmente para questões voltadas para geração de renda e acesso a bens e serviços de populações carentes, buscando soluções democráticas e sustentáveis (RODRIGUES e BARBIERI, 2008). O processo de incubação se dá então tanto como um processo educativo, onde se busca a articulação entre os saberes populares com os saberes acadêmicos, como um processo de crítica social e produção de conhecimento, voltado para a melhor compreensão dos processos necessários à sustentabilidade da economia solidária, e o estabelecimento de estratégias voltadas para sua implementação (CULTI, 2007).

No entanto, a implementação de tal função crítica pelas incubadoras encontra dificuldades. A própria descontinuidade de produção acadêmica sobre $\mathrm{o}$ tema $\mathrm{e}$ a prevalência de estudos sobre empreendimentos, nos mostram a centralidade do ato reflexivo em um aspecto 
muito restrito das possibilidades oferecidas pela economia solidária, que tem justamente na ampliação da aplicabilidade de princípios de autonomia e solidariedade voltados para diferentes etapas dos processos econômicos e sociais, sua diferenciação em relação a outros modelos econômicos (SINGER, 2001).

Nesse sentido, a proposta do presente capítulo é ampliar a noção de objeto de incubação no âmbito das incubadoras de economia solidária. Iremos abordar os três elementos que consideramos ser mais pertinentes, por abordarem diferentes níveis nos quais o processo de incubação pode se dar, e por estarem relacionados a diferentes perspectivas metodológicas que se mostram necessárias para a implementação dos processos de incubação em cada um desses níveis, que serão o empreendimento, a comunidade e o território.

\section{Três níveis dos processos de Incubação}

Não existe ainda uma definição formal e legal do que seja um empreendimento de economia solidária (EES). Embora a maior parte dos empreendimentos se estruturem como associações ou cooperativas, tais estruturações legais não são suficientes para as possibilidades de expressão das atividades econômicas propostas pela economia solidária. Além disso, essas expressões estão ligadas a movimentos sociais e formas de organização econômicas populares europeias que não encontram correspondências, enquanto movimentos próprios, nas culturas latino-americanas, que, diferentes dos modelos europeus, são muito mais marcadas pela informalidade (GAIGER, 2014).

Uma definição geral do que é um EES nos é fornecida por Culti (2010, p.3) como sendo "organizações coletivas organizadas sob a forma de autogestão que realizam atividades de produção de bens e de serviços, crédito e finanças solidárias, comércio e consumo solidários". Podemos perceber, no entanto, que nessa definição somente nos remete aos princípios da economia solidária de solidariedade e autogestão que vão definir o que seria o EES.

Essa referência, no entanto, se mostra necessária, em função de que se pode encontrar tanto grupos informais, associações e cooperativas que não se caracterizam, nem em suas práticas, nem em seus objetivos (além dos valores que as regem), como empreendimentos que busquem a aplicação dos valores ligados a economia solidária (OGANDO, 2013). Essa proximidade com outras formas institucionais tem inclusive se mostrado como um dos principais entraves para a 
caracterização legal dos empreendimentos de economia solidária (SILVA e SILVA, 2015). Nesse sentido, uma melhor definição formal, pelo caráter coletivo e legal de sua estruturação seria o dado pelo artigo $4^{\circ}$ do $\mathrm{PL} \mathrm{n}^{\circ}$ 4.685/2012 (BRASIL, 2012).

Embora restrinja as possibilidades de entendimento ou de inserção de experiências dentro do leque da economia solidária essa definição possibilita uma referência para a relação formal entre a economia solidária e o estado, inserindo a economia solidária como proposta ampla de organização social e econômica e não só como uma alternativa informal para situações e momentos de crise. Além disso, estabelece a economia solidária, e seus empreendimentos como objeto não só de políticas de fomento, mas como sujeitos de direito (GAIGER, 2015).

Embora existam críticas quanto a esse processo de formalização, em função de sua cooptação pela estrutura burocrática do estado a serviço do capital (GHIZELINI, 2015) tais críticas precisam ser localizadas dentro de um contexto mais amplo. Segundo Lisboa (2005) embora não sejam voltadas para as determinações de mercado ou dos preceitos do capital, os EESs devem ser considerados como inseridas dentro da perspectiva de mercado, se diferenciando assim de outras ações não mercantis e não monetárias, como as ligadas à economia da dádiva (MAUSS, 2015), ou à noção de terceiro setor.

No entanto, a relação dos EESs com os valores ligados ao mercado está muito mais atrelada à dimensão de sustentabilidade dos empreendimentos do que na determinação de sua lógica de existência. A isso se soma o fato de, além de estar inserido dentro de um contexto mercado, o EES também se insere dentro de um contexto de necessidades gerenciais, que englobam tantos os elementos de uma racionalidade administrativa, quanto os de uma racionalidade social à qual o empreendimento se destina, instaurando um conjunto ainda maior de complicadores para o processo de formalização dos EES (GAIGER, 2014).

Podemos considerar a existência de um processo dialético entre a racionalidade administrativa e a racionalidade social do empreendimento, dentro do que Carvalho e Pires (2001) chamam de Princípio da Diferenciação, ou seja, em função da diferença entre os princípios que os regem e os princípios do ambiente no qual eles se inserem. O EES então deve ser analisado sempre como espaço de inserção conflitiva, onde existe a necessidade de lidar tanto com demandas oriundas do trabalho quanto do capital, da lógica administrativa e da lógica 
social, dos valores de autonomia e das imposições heterônomas.

O processo de incubação, ao considerar o EES deve então levar em conta sua estrutura híbrida, porém levando também em conta a mudança de relações de trabalho que ela propicia, e das consequentes novas possibilidade se sociabilidades que ela instaura. O EES deve ser então pensado dentro de uma compreensão da economia solidária como um modelo de organização social ampla, e não só um modelo gerencial/burocrático/monetarista de organização voltada para inserir grupos sociais marginalizados, diminuindo assim os impactos negativos da lógica do capital de organização das relações sociais, e assim, a serviço de um refinamento da mesma (GHIZELINI, 2015).

Porém, esse movimento amplo, se estrutura por meio de diversas manifestações organizadas (como fóruns e redes), dos quais as incubadoras são somente uma parte. E embora possuam a capacidade de engendramento de situações de economia solidária não tem no movimento como um todo seu objeto de ação. No entanto, o ato de incubar também pode (e deve prioritariamente) ser direcionado para o âmbito do social, dentro de uma perspectiva que ultrapasse a dimensão do EES.

\section{A Comunidade como objeto de incubação}

A noção de comunidade vem se desenvolvendo de forma diversa em diferentes autores, e não pretendemos abarcar a todos nem fazer uma revisão teórica dessas perspectivas. No entanto, é importante entender aqui que a noção de comunidade, para servir aos propósitos de se estruturar como um objeto de incubação na economia solidária, vai naturalmente ter ressaltada sua dimensão econômica, tanto no sentido de produção quanto de compartilhamento de bens (sejam esses materiais ou simbólicos) e serviços. Então, embora questões como o compartilhamento de uma língua ou religião, relações de parentesco, vizinhança ou amizade, ou mesmo a percepção de pertença a um mesmo grupo ou situação (PERUZZO e VOLPATO, 2009) sejam fatores importantes, não adquirem, no nosso caso a centralidade do processo explicativo. Consideraremos dois aspectos que definiriam ao nosso ver a melhor noção de comunidade, para fins de pensar a participação dessas como objetos de incubação, sendo o primeiro, a participação em laços de reciprocidade (MAUSS, 2015), e o segundo, o estabelecimento de laços de 
convivência, que permitam a estruturação de processos psíquicos compartilhados referentes à vida cotidiana, como a memória, e a atribuição de sentido e afeto ao tempo e espaço (BOSI, 2004).

$\mathrm{O}$ primeiro aspecto se refere ao estabelecimento de relações entre pessoas e grupos que se dê em função da inserção dessas em uma série de obrigações uns para com os outros, que se aplique a aspectos amplos da vida cotidiana, mas principalmente em termos de trocas de bens simbólicos e materiais nas quais o pagamento da prestação recebida, ao invés de liquidar a relação entre as pessoas gerada por aquela obrigação, a mantêm, reforçando ainda mais o laço entre os sujeitos. É o que Mauss (2015) chamou de economia da Dádiva. Na dádiva, a relação de valor não se dá de forma monetária, onde uma coisa vale uma quantidade pré-estabelecida de outras coisas. É o ato de retribuição que é estabelecido com a entrada no sistema de obrigação da dádiva, mas sem uma monetarização possível dessa obrigação.

No entanto, não seria somente o estar ligado a obrigações que estabeleceria uma comunidade, mas, além disso, também o compartilhar, de forma íntima, aspectos do cotidiano, e da construção de si frente a esse cotidiano. A pura coabitação, ou a participação comum a uma língua ou religião, não é condição suficiente para que estes desenvolvam processos psíquicos compartilhados, como a construção de espaços mnemômicos associados a aspectos do ambiente compartilhado pelas pessoas, ou atribuição de sentidos e afetos compartilhados a esses locais e/ou a momentos (BOSI, 2004).

O que chamamos aqui de comunidade seria a articulação de pessoas e ambientes associados por essas duas condições, que embora interligadas, indicam aspectos das vivências dos sujeitos em relação uns aos outros que não podem ser reduzidas, nem ao aspecto social, nem ao psíquico, mas que, ao mesmo tempo em que considera a ambos.

A estruturação da comunidade como um objeto para o trabalho de incubação se dá principalmente pela identificação dos elementos fomentadores desses laços de reciprocidade e de convivência, da forma como esses se estruturam, e a identificação dos elementos que inibem ou impedem que esses laços se estruturem, buscando atuar, para além dos aspectos especificamente monetários, ou de renda direta que possa ser aferida por um empreendimento específico, mas abarcando o desenvolvimento e a sustentabilidade psicossocial de todos os ganhos e suportes sociais à reprodução material da vida e da força de trabalho que 
são disponibilizados pelo grupo social e comunitário no qual o sujeito está envolvido. (CARVALHO e PIRES, 2001).

Um primeiro passo então para o processo de incubação de comunidades dáse em relação às instituições de referência que são os espaços institucionais (ainda que pouco formalizados) que intermediam as relações entre as pessoas da comunidade (VISEU, 2009). A identificação, compreensão e fomento para o desenvolvimento dessas estruturas é um dos pontos chaves para a elaboração de um projeto de desenvolvimento econômico local que leve em conta a participação da população nesse processo, pois são atores que norteiam a compreensão e a adesão das pessoas a esses projetos (CARVALHO \& PIRES, 2004).

\section{Segundo Warren (2006) as} organizações de referência constituem-se como núcleos abertos à participação democrática dos sujeitos que, além de perenizarem esses laços também lhe atribuem uma dimensão institucional. Segundo Gaiger (2004) a abordagem dessas organizações de referência é um procedimento privilegiado para a identificação de processos organizativos sociais e de trabalhadores por possibilitarem o acesso à compreensão dos fenômenos que aparecem como dispersos.
No entanto, apesar da referência à essas instituições ser importante, não se constituem como um fim em si, mas em função de servirem como mediadoras no processo de pesquisa, pois remetem às experiências e atores sociais específicos, onde o real dos processos de organização social de enlaçamento e resistência acontece, sendo necessário sempre manter uma postura crítica frente à atuação dessas instituições (PIRES et al., 2013).

Embora na comunidade possa se estruturar, a partir do fomento dos laços e de uma cultura de solidariedade, empreendimentos de grupos específicos dentro dessa comunidade também podemos buscar a estruturação de espaços de produção e distribuição de bens que não passem especificamente por empreendimentos formais estruturados nos moldes de empresas. Nesse sentido iniciativas como jardins produtivos ou hortas comunitárias, assim como um sistema de troca de serviços, ou mutirões para construção, são exemplos de ações que geram acesso a bens e serviços, com íntima vinculação comunitária, mas que não passam pela estruturação de empreendimentos, nos moldes do artigo $4^{\circ}$ do projeto de lei $\mathrm{n}^{\circ} 4.685 / 2012$.

No entanto, além da identificação e fomento desses espaços que onde as 
relações de solidariedade se estruturam, é necessário também compreender como se dão, em cada comunidade, os processos de apropriação e construção coletiva dos espaços e capacidades de trabalho e produção na comunidade.

Essas apropriações coletivas de sentido sobre a realidade podem ser analisadas a partir do que Bosi (1993) chama de memória social. A autora parte do princípio de que as atribuições de sentido às vivências e às coisas não se resumem a atividades subjetivas, mas se dão a partir dos laços intersubjetivos entre os indivíduos, atuando não só como atividade de recuperação de dados passados, mas como uma integração de fluxo de sentido entre passado e o momento presente, sendo uma organizadora dos sentidos atribuídos ao presente. Segundo Bosi (2004), essas memórias e sentidos não são arquivados somente na mente das pessoas, mas em todos os seus aparatos e artefatos culturais.

Segundo Borges (2010) esse processo de rememoração não se dá de forma unívoca, e sem conflitos, havendo diferentes atribuições de sentidos e valores, por diferentes grupos em uma mesma comunidade, aos artefatos e bens culturais de seu cotidiano, localizando o sujeito também em uma história dinâmica e conflitiva no estabelecimento dos laços sociais entre os membros da comunidade, da apropriação que estes realizam desses bens e das estruturas históricas de poder presentes.

Bosi (2003) vai dizer que os bairros das grandes cidades não possuem história, possuem biografia, narrada por seus moradores e que contam histórias sobre seu espaço físico e humano, seus acontecimentos, grandes e pequenos, bons e maus. E que o silêncio sobre esses fatos, e o decorrente esquecimento, levam à falência dos projetos da cidade, à dispersão e à ruptura com a vida cotidiana. Também nas pequenas comunidades, essas atividades vão ser de grande importância, pois ativam a capacidade de intencionalidade nos sujeitos e possibilitam também a ressignificação das atividades e laços sociais de forma não fragmentada (SALUM e MAHFOUD, 2006; MACHADO, 2006).

A consideração da memória da comunidade se dá em função de não buscar a criação de estruturas artificiais, que, por mais bem-intencionadas que sejam não encontrariam sustentação na dinâmica social ou psicossocial das comunidades. A ação da economia solidária, nesse sentido, deve-se pautar muito mais em função de possibilitar que tanto os laços de solidariedade e reciprocidade, quanto a busca por uma organização material dos 
membros da comunidade, ocorram de forma autônoma e articulada com as características culturais, ambientais e históricas dessas comunidades, deixando que a própria comunidade encontre suas formas de manifestação dos laços de solidariedade.

Porém, para além dessa dimensão comunitária, onde os processos sociais e psíquicos são estruturados a partir da vivência conjunta de significação das atividades cotidianas, existe um terceiro nível, que a nosso ver, também é importante para o processo de incubação, principalmente para se pensar os processos econômicos a partir de uma visão mais ampla, tanto em termos de cadeias produtivas quanto em termos de propostas de organização econômica denominada Território.

\section{O território como objeto de incubação}

O conceito de território, embora trabalhado de maneira diferenciada por vários autores, é marcado por dois elementos chave. O primeiro se dá a partir da noção de poder, ou de arranjos de poder, tanto no nível público quanto privado, englobando aspectos amplos, como autoridade governamental, os acessos a recursos financeiros e produtivos, e a legitimidade para construção de interpretações simbólicas sobre a realidade, e a distribuição no espaço e tempo da influência desses arranjos, que podem ocorrer de forma sobrepostas, tanto conflitiva quanto cooperativamente. $\mathrm{O}$ segundo, intimamente associado ao primeiro, é a noção de apropriação, ou seja, do território como espaços de dinâmicas específicas de apropriação ou não dos bens materiais e simbólicos, ou da definição dos sentidos e transformações a serem construídas naqueles espaços (BORDO et al, 2004).

Apesar dessa multiplicidade de possibilidades de interpretação da noção de território, o mais importante para nosso caso, a questão econômica, e dentro dela, principalmente a forma de pensar e organizar o trabalho e o acesso a seus produtos é a que se faz mais premente. Nesse sentido, a estruturação do estado e das políticas públicas, os elementos culturais e as estruturações econômicas existentes, embora tenham dinâmica própria e possam ser analisadas de maneira específica e isolada, também podem ser analisadas em função de sua determinação para um aspecto específico. As relações de trabalho e de produção podem ser então compreendidas a partir da função do território de servir como elemento intermediador, para o sujeito, entre o espaço vivido da atividade produtiva e o Mundo (SANTOS, SOUZA e SILVEIRA, 2002). 
Essa apropriação do termo território, embora possa destoar de seu uso mais restrito, também pode fornecer elementos que possibilitem uma maior expansão da compreensão do conceito. Nesse sentido, a noção de Território que aqui propomos se diferencia da noção de Comunidade, no sentido em que, nessa os fenômenos que seriam objetos de intervenção seriam justamente os elementos de interpretação do espaço e de si que são construídos conjuntamente, ainda que nela se envolvam elementos conflitantes, enquanto, no primeiro, o objeto de intervenção são construções de formas institucionais e relacionais, que, embora se apresentem sobrepostas e em constante relação com outras formas, não são necessariamente atos de compartilhamento da produção de si e de si em relação ao espaço, mas instrumentos materiais ou simbólicos que representam relações de poder e apropriação sobre o espaço vivido pelas pessoas, e que intermediam a relação dessas uma com as outras e com os espaços, tanto local, quanto o espaço mais amplo do mundo.

Nesse sentido, o processo de incubação do território vai passar por dois grandes grupos de elementos determinadores do poder nos territórios, ou seja, o poder público, e as cadeias produtivas dos setores envolvidos, consideradas amplamente, envolvendo tanto aspectos relacionados a produção e a distribuição, mas também outros, como elementos de capacitação profissional e desenvolvimento de tecnologias e produtos. Embora possam ser analisados de forma separada, ambos estão intimamente interligados, sendo que um fomenta as práticas e compromissos dos outros.

Antes de passar para análise das práticas associadas ao processo de incubação dos territórios, é necessário, no entanto, ressaltar o caráter holístico da economia solidária, ou seja, sua capacidade de fornecer um modelo amplo de organização econômica, e por consequência, também social e cultural (ROCHA FILHO e CUNHA, 2015), e rechaçar uma compreensão da economia solidária como uma forma, ainda que disfarçada, de ações ou políticas compensatória, voltada aos mais pobres, que se mostra amplamente presente em alguns discursos de inserção social por meio da economia solidária.

Além dessas questões relacionadas às classes sociais, ou a cadeias e perfis produtivos, a dimensão holística da economia solidária também se mostra como um elemento que envolve aspectos mais amplos, como questões culturais ou ecológicas. Nesse sentido, as práticas de incubação de territórios também precisam 
ser sustentáveis tanto do ponto de vista cultural, possibilitando a promoção de uma cidadania cultural (FARIA, SERRA, 2016), quanto a sustentabilidade ecológica de suas práticas (SCHMITT, 2010).

Segundo Oliveira (2007), sob um discurso desenvolvimentista, muitas vezes mascara-se a atribuição de fundos públicos ao capital, em uma lógica desvinculada dos elementos endógenos do território. A alternativa esse modelo predatório seria a gestão compartilhada do território por meio do domínio público das políticas e ações estatais. As ações voltadas para o poder público então devem buscar não sua instrumentalização pela economia solidária, mas a abertura para que os trabalhadores e produtores locais possam se beneficiar das políticas de desenvolvimento econômico, em todos seus aspectos, envolvendo desde compras públicas das entidades estatais dos produtores locais, ao fomento de infraestrutura, capacitação técnica, acesso a crédito e adequação de regras ligadas à produção, como as regras sanitárias, de segurança ou legais.

Aqui é importante ressaltar a diferença na lógica do empreendimento para a lógica do território no processo de incubação. O empreendimento, nesse caso, não é o centro do processo de interferência no território e nas entidades do poder público nele presente, mas a própria democratização do acesso à gestão, e o estabelecimento de laços de solidariedade entre as entidades públicas e os produtores locais. O desenvolvimento por meio da economia solidária deve ser encarado como uma possibilidade, que, se mais efetiva na garantia da melhor consecução dos objetivos desses empreendimentos, das entidades do poder público e da sociedade de forma geral, deve então ser utilizada.

No entanto, isso não significa que a economia solidária não deva ser fomentada. Pelo contrário, como nos mostra Lima (2012), a organização dos produtores e trabalhadores por meio da economia solidária muitas vezes é uma condição para que estes possam participar de forma organizada e clara da definição das políticas públicas de desenvolvimento territorial. Essa organização, no entanto, não deve se sobrepor à democratização mais ampla da gestão do território.

No entanto, a organização meramente política não deve ser o centro do processo de articulação dos empreendimentos, devese buscar uma articulação produtiva entre os empreendimentos, os seus entes de representação e organização e os entes do poder público que lhes fomentam, tendo como referência a busca de apropriação das cadeias produtivas locais dentro dos 
processos relacionados à economia solidária. Como nos mostram Dias et al (2014), ao invés de buscar laços de complementariedade entre empreendimentos congêneres, na economia solidária, o que se nota é a dos empreendimentos se colocarem em uma situação de funcionalidade subordinada dos EESs com os empreendimentos da economia tradicional, ou sua manutenção como entidade isolada atuando informalmente. Essa situação de isolamento na prática produtiva geraria um baixo ganho de consciência, mobilização, capacitação e organização nos membros desses EESs e no movimento de economia solidária de maneira geral.

Ainda que existam entidades como fóruns e conselhos locais de economia solidária, sua restrição à atuação política, não possibilita a compreensão de processos econômicos pensados de forma mais ampla. Pelo contrário, na articulação entre empreendimentos, o próprio ato de produzir conjuntamente deve ser entendido como ato político constitutivo da economia solidária (PIRES et al., 2013).

Em termos práticos, o processo de incubação nesse caso passa pela apropriação das potencialidades produtivas locais dos territórios, buscando identificar elementos que possam ser apropriados pelo trabalho, e que estejam associados a outros empreendimentos já estruturados. Busca-se então identificar tanto a produção de matéria prima, seus diversos meios de transformação, e os processos de comercialização e distribuição desses produtos, e tenta-se identificar formas de estruturar tais ações em termos de processos e empreendimentos de economia solidária. Além disso, busca-se identificar os grupos, que, já por afinidade ou já por processo de acumulação de experiência de associação solidária e autogestionária, estariam mais propensos a aderirem a processos e empreendimentos de economia solidária, e a partir de então, à implementação de ações voltadas para disseminar a proposta da economia solidária e tentar adequar à realidade produtiva e cultural desses grupos e pessoas.

Nesse processo é importante compreender que o estabelecimento de cadeias produtivas solidárias passa também pela apropriação coletiva dos excedentes (SCHIOCHET e BRANDES, 2009). Nesse processo, mais uma vez, a lógica do EES pensado isoladamente em termos econômicos, ainda que politicamente estejam associados, precisa ser revista. Nesse sentido discordamos de Mance (2003), para quem a articulação entre os EES dentro de uma cadeia produtiva se daria a partir do princípio da solidariedade, 
pois, essa solidariedade ainda teria como centralidade os EES. Consideramos que seria mais adequada, quando pensamos em termos territoriais, a construção de lógicas de articulação mais institucionalizadas como a criação de associações e cooperativas de $2^{\circ}$ e $3^{\circ}$ grau, para que não ocorra a cisão entre a atividade política e a atividade produtiva na economia solidaria (PIRES et al., 2013). Só quando essa cisão necessariamente ocorre, como na relação entre as entre as entidades da economia solidária e as do estado, como a universidade, os fóruns, conselhos e outros entes de articulação especificamente política se mostram mais adequados.

Repensar essa articulação entre os empreendimentos também é importante para podermos repensar a estruturação de cadeias produtivas, e da necessária acumulação de recursos dentro do modelo de economia solidária. Além da capacidade de trabalho dos membros dos EESs é preciso entender que estes só vão conseguir avançar em termos de produtividade com alocação de recursos em sua capacidade produtiva, por meio da adaptação ou do desenvolvimento de uma capacidade sociotécnica potencializadora dessa capacidade produtiva que seja adequada às relações de trabalho baseadas na solidariedade e na autogestão. (DAGNINO, 2000).
A adaptação sociotécnica nesse sentido, quando pensada em micro e nano cadeias produtivas, onde não vai haver uma necessidade de desenvolvimento técnico compartilhado é possível abordando somente o conhecimento já compartilhado, onde a informalidade dos empreendimentos também pode se reproduzir na informalidade da articulação entre os mesmos (SPINK, 2009). Porém, à medida que a cadeia produtiva incorpora mais elementos técnicos, consideramos que a criação de EES mais complexos e estruturados, que incorporem, ainda que de forma secundária (como no caso de associações ou cooperativas de $2^{\circ}$ grau) a organização da produção e da gestão dos EES, seja mais interessantes como elementos articuladores dessas cadeias produtivas, pois, diferente das micro cadeias produtivas, ligadas à lógicas informais, com a inserção em cadeias produtivas mais articuladas, a necessidade de se relacionar economicamente com empreendimentos tradicionais, acaba gerando uma captura da lógica gerencial e de organização do trabalho nos EES que os descaracterizam de sua finalidade inicial de promoção de solidariedade e autogestão (FARIA et al., 2008).

\section{Conclusão}


A atividade das Incubadoras Universitárias de Economia Solidária, embora venha se estruturando a alguns anos, ainda se encontra em processo de construção de seu marco referencial. Da mesma forma, a própria construção de uma comunidade de pesquisadores sobre o tema também se encontra em processo de estruturação, sendo que a maioria dos estudos na área ainda uma atividade secundária e descontinuada para seus realizadores.

Nesse contexto pretendeu-se com esse texto buscar a construção de um marco referencial, ainda que introdutório, das possibilidades de atuação das incubadoras de economia solidária, e ressaltar a necessidade de pensar a ação dessas incubadoras como ações voltadas prioritariamente para a construção de novas formas de sociabilidade e de construção de lógicas produtivas, e não somente na criação de empreendimentos e de geração de trabalho e renda.

Embora essas ações sejam necessárias, e seja através delas que a economia solidária se materializa em sua maior parte, a lógica que rege os empreendimentos não deve ser percebida como central para a economia solidária, mas sim, estes empreendimentos devem ser percebidos como instrumentos de concretização dessas novas formas de sociabilidade e de organização do trabalho pautadas em princípios da solidariedade e da autogestão.

Existe um caminho ainda grande pela frente, e a universidade tem um papel de extrema importância na construção conceitual e técnica que possibilite que esses princípios possam ser implementados de forma prática nos empreendimentos. Porém, essa construção demanda, além de uma ação mais sistemática e continuada de pesquisadores. Além disso, como a maior parte dessas ações se dão por meio de projetos de extensão, a própria concepção de extensão deve ser repensada, principalmente na consideração de um de seus objetivos e como critério de avaliação da produção dessas incubadoras também a construção de espaços onde outros atores no campo da economia solidária possam participar de forma mais objetiva $\mathrm{e}$ construtiva dessas construções conceituais e técnicas. Para que isso ocorra, as incubadoras, além de estruturarem suas atividades para a criação de empreendimentos e processos de economia solidária, precisam se voltar também para a capacitação mais ampla, tanto dentro da universidade, como para elementos externos, principalmente os membros do poder público (incluindo entidades estatais e não estatais), e dos próprios trabalhadores. 
Com isso esperasse que a economia solidária não surja como uma demanda da precariedade do sistema produtivo capitalista, mas como a organização a partir de uma cultura solidária e autogestionária, ligada às nossas tradições culturais emancipatórias, que crie demandas próprias de organização, e as destine às incubadoras, na perspectiva de receber, por meio das mesmas, o acesso aos serviços e conhecimentos do sistema universitário.

\section{Referências}

BORDO, A.A.; SILVA, C.H.P.; NUNES, M.; BARBOSA, T.; MIRALHA, W. Diferentes abordagens do conceito de território. 2004. Disponível em http://forumeja.org.br/sites/forumeja.org.br/files/diferentesabordterr.pdf. Acessado em $27 / 04 / 2017$.

BORGES, C. M. A memória e os espaços sagrados: Os colonos e a apropriação simbólica dos lugares. Locus: Revista de História, v. 16, n. 2, p. 119-130, 2010. Disponível em http://www.editoraufjf.com.br/revista/index.php/locus/article/view/1055. Acessado em 04/04/2017.

BOSI, E. Pesquisa em Memória Social. Revista Psicologia USP, v. 4 n. 1-2, p. 277-284, 1993. Disponível em http://www.revistas.usp.br/psicousp/article/download/34480/37218 Acessado em $25 / 10 / 2013$.

BOSI, E. Memória da Cidade: Lembranças Paulistas. Estudos avançados v. 17, n. 47, p. 197-211, 2003. Disponível em http://www.scielo.br/scielo.php?pid=S010340142003000100012\&script=sci_arttext. Acessado em 25/10/2013.

BOSI, E. Memória e sociedade: lembranças dos velhos. São Paulo: Companhia das Letras, 2004.

BRASIL. Projeto de Lei $\mathbf{n}^{\circ} \mathbf{4 6 8 5}$ de 2012. Disponível em http://www.camara.gov.br/proposicoesWeb/prop_mostrarintegra;jsessionid=74626556BA159FC 09AA29CE56A574C48.proposicoesWebExterno2? codteor $=1037445 \&$ filename $=P L+4685 / 2012$.

CALBINO, D; PAULA, A.P.P. Economia Solidária: investigação sobre o estado da arte. Gestão Contemporânea, Porto Alegre, v. 10, n. 14, p. 371-397, 2013. Disponível em http://seer4.fapa.com.br/index.php/arquivo/article/viewFile/302/145.

CARVALHO, R.A.; PIRES, S.D. Em busca de novas solidariedades: os empreendimentos da economia social em questão. Sociedade e Estado, n.16 v. 1-2, p. 159-185, 2001. Disponível em http://www.scielo.br/scielo.php?script=sci_arttext\&pid=S0102-69922001000100008, acesso em 03 de fevereiro de 2018.

CHAUI, M. Conformismo e Resistência: aspectos da cultura popular no Brasil. 6a ed. São Paulo: Editora Brasiliense, 1996. 
CULTI, M.N. Economia solidária: Incubadoras universitárias e processos educativos. Proposta, v. 31, n. 111, p. 16-22, 2007. Disponível em http://www.unitrabalho.uem.br/administracao/bd_artigos/arquivos/010614153016.pdf. Acesso em 03 de fevereiro de 2018.

CULTI, M.N. Economia Solidária no Brasil: Tipologia dos Empreendimentos Econômicos Solidários. São Paulo. Ed. Todos os Bichos. 2010.

DAGNINO. R. . Em direção a uma Estratégia para a redução da pobreza: a Economia Solidária e a Adequação Sócio-técnica. OEI, 2000. Disponível em http://www.oei.es/historico/salactsi/rdagnino5.htm. Acesso em 05 de fevereiro de 2018.

DIAS, R.B. et All. Tecnologia Social e Economia Solidária: construindo a ponte. Revista Latinoamericana de Políticas y Acción Pública v. 1, n, 1, p. 59-78. 2014. Disponível em http://repositorio.flacsoandes.edu.ec/bitstream/10469/6443/1/RFLACSO-MP1-04-GAPI.pdf.

DUBEUX, A. O papel das universidades na construção da economia solidária no Brasil. Proposta, v. $31, \quad$ n. 111, p. 3-15, 2007. Disponível em http://fase.org.br/wpcontent/uploads/2007/03/proposta-111-final.pdf., Acesso em 05 de fevereiro de 2018.

FARIA, H., SERRA, N. Economia Solidária da Cultura e Cidadania Cultural. Editora UFABC: Santo André, 2016.

FARIA, M.S.; DAGNINO, R.; NOVAES, H.T. Do fetichismo da organização e da tecnologia ao mimetismo tecnológico: os labirintos das fábricas recuperadas. Revista Katálise, v. 11 n. 1 p. 123 131, 2008. Disponível em https://periodicos.ufsc.br/index.php/katalysis/article/viewFile/5394/4738. Acesso em 23 de maio de 2017.

GAIGAER Luiz Inácio Germany. (Org)Sentidos e experiências da economia solidária do Brasil. Editora da UFRGS, Porto Alegre, 2004.

GAIGER, L.I.G. O Mapeamento Nacional e o Conhecimento da Economia Solidária. Revista da ABET, v. 12, n. 1, p. 7-24, 2014. Disponível em http://base.socioeco.org/docs/_ojs_index.pdf. Acesso em 05 de fevereiro de 2018.

GAIGER, L.I.G. The legal framework for Solidarity Economic Enterprises in Brazil: backgrounds and perspectives. 5th EMES International Research Conference on Social Enterprise Building a Scientifc Fild to Foster the Social Enterprise Eco-Sistem. HElsink, 2015. Disponível em http://emes.net/content/uploads/publications/the-legal-framework-for-solidarityeconomic-enterprises-in-brazil-backgrounds-and-perspectives/ESCP-5EMES-

10_Lega_framework_solidarity_Economic_Entreprises_Brazil_Gaiger.pdf. Acesso em 05 de fevereiro de 2018.

GHIZELINI, A.A.M. Reflexões uma crítica à economia solidária: do materialismo histórico à teoria da ação. Revista Escritos, v. 11, n.2, 1-19, 2015. Disponível em http://faculdadebagozzi.edu.br/wp-content/uploads/2016/01/Revista-Escritos-v.11-n.2-2015.pdf. Acesso em 05 de fevereiro de 2018. 
LIMA, J.S. Desenvolvimento Territorial e Economia Solidária: das concepções e práticas entre o Estado brasileiro e os coletivos organizados no Território do Sisal-BA. Revista Espaço Acadêmico, n. 131, p. 172-180, 2012. Disponível em file://C:/Users/Admin/Desktop/economia\%20solid\%C3\%A1ria $\% 20 \mathrm{e} \% 20$ desenvolvimento\%20t erritorial.pdf. Acesso em 09 de maio de 2015.

LISBOA, A. M.. Economia solidária e autogestão: imprecisão e limites. RAE. Revista de Administração de Empresas, v. 45, n. 3, p. 109-115, 2005. Disponível em http://www.scielo.br/pdf/rae/v45n3/v45n3a06.pdf. Acesso em 05 de fevereiro de 2018.

MACHADO, M. C. (Re)significações no mundo rural mineiro: o carro de boi do trabalho ao festar (1950-2000). Revista Brasileira de História, v. 26, n. 51, p. 25-45. 2006. Disponível em http://www.scielo.br/scielo.php?pid=S0102-01882006000100003\&script=sci_arttext. Acessado em 04/04/2017

MANCE, E. Cadeias produtivas solidárias. In CATANNI, D. A Outra Economia. Porto Alegre: Editora Veraz, p. 26-28. 2003.

MAUSS, M. Sociologia e antropologia. São Paulo: Cosac \& Naify, 2015.

OGANDO, C.B. As Fronteiras da Economia Solidária. Uma análise a partir do Mapeamento Nacional. 2013. Disponível em http://www.socioeco.org/bdf_fiche-document-3533_pt.html. Acesso em 05 de fevereiro de 2018.

OLIVEIRA, F.J.G. Reestruturação econômica, poder público e desenvolvimento social: possibilidades de disputa e de recomposição de poder no território. Revista Electrônica de Geografia y Ciências Sociales, v. 11, n. 245, p. 0-0, 2007. Disponível em http://www.ub.edu/geocrit/sn/sn-24565.htm. Acesso em 09 de maio de 2017.

OLIVEIRA, M.C.S.B., ZANIN, M. Economia Solidária: Uma temática em evolução nas dissertações e teses brasileiras. Revista Brasileira de Ciência, Tecnologia e Sociedade, v. 2, n. 1, pp. 181-193, $2011 . \quad$ Disponível http://www.revistabrasileiradects.ufscar.br/index.php/cts/article/viewFile/121/69. Acesso em 05 de fevereiro de 2018.

PERUZZO, C.M.K; VOLPATO, M.O. Conceito de Comunidade, local, e região: inter-relações e diferenças. Líbero, v. 12, n. 24, p. 139-152 2009. Disponível em http://www.revistas.univerciencia.org/index.php/libero/article/viewFile/6790/6132. Acesso em 30 de março de 2017

PINHEIRO, D.C. O Estado da Arte da Produção Científica em Economia Solidária. Administração Pública e Gestão Social, v. 8, n. 2, p. 95-103, 2016. Disponível em http://www.apgs.ufv.br/index.php/apgs/article/view/843\#.WOOfBE9Viko. Acesso em 04/04 de 2017.

PIRES, S. D. A dimensão psicossocial da autonomia em cooperativas de trabalho, 09/12/2005, (200f) Dissertação de Mestrado em Psicologia, UFMG. Belo Horizonte, 2005.

PIRES, S.D. Perlaboração de Mecanismos defensivos em relação ao trabalho em empreendimentos de economia solidária. Desenvolve Revista de Gestão do Unilasalle, v 7, n 1, (no prelo), 2018. 
PIRES, S.; COUTO, G.; ALVES, A. Constituição dos mecanismos de defesa psíquicos e sociais no trabalho autogestionário. In: VASCONCELOS-SILVA, A.; BUENO, M. (Org.). Novas concepções sobre organizações e trabalho. Catalão: Editora UFG, p. 158-170, 2013.

ROCHA FILHO, A.N.; CUNHA, L.A.G. Economia Solidária para qual desenvolvimento territorial? Anais do I Congresso de Pesquisadores de Economia Solidária (CONPES). São Carlos, 2015. Disponível em http://docplayer.com.br/34404190-I-conpes-congresso-depesquisadores-de-economia-solidaria.html. Acesso em 05 de fevereiro de 2018.

RODRIGUES, I.; BARBIERI, J.C. A emergência da tecnologia social: revisitando o movimento da tecnologia adequada como estratégia de desenvolvimento sustentável. Revista de Administração Pública, v. 42, n. 6, p. 1069-1094, 2008. Disponível em http://www.scielo.br/scielo.php?pid=S0034-76122008000600003\&script=sci_abstract\&tlng=pt. . Acesso em 05 de fevereiro de 2018.

SALUM, C. C.; MAHFOUD, M. Produção de Imagem e Cultura: A criação de uma bandeira em uma comunidade tradicional. Anais do III Seminário Internacional de Pesquisa e Estudos qualitativos e V Encontro de Fenomenologia e Análise do Existir, São Paulo. 2006. Disponível em http://www.sepq.org.br/IIIsipeq/anais/pdfs/pmchf3.pdf. Acesso em 04/04/2017. Acesso em 05 de fevereiro de 2018.

SANTOS, M.; SOUZA, M. A. A. de; SILVEIRA, M. L. (org.). Território: globalização e fragmentação. São Paulo: Hucitec; Annablumme, 2002

SCHIOCHET, V.; BRANDE, M.E. Espaço e Cadeias Produtivas Solidárias. O Caso da Reciclagem. III Encontro Catarinense de Economia, Blumenau, 2009. Disponível em http://base.socioeco.org/docs/artigo_45.pdf. Acesso em 23 de maio de 2017.

SCHMITT, C.J. Economia Solidária e Agroecologia: Convergências e desafios na construção de modos de vida sustentáveis. Revista Mercado de Trabalho (IPEA), n. 42, p. 55-64, 2010. Disponível em http://repositorio.ipea.gov.br/bitstream/11058/4050/1/bmt42_08_Eco_02_convergencias.pdf. Acesso em 05 de fevereiro de 2018.

SILVA, F.L. Universidade: A ideia e a história. Estudos Avançados, v. 20, n.56, p. 191-202, 2006. Disponível em http://www.scielo.br/scielo.php?script=sci_arttext\&pid=S010340142006000100013. Acesso em 05 de fevereiro de 2018

SILVA, R.F.; SILVA, S.P. Em busca de um marco legal para a Economia Solidária no Brasil: Análise da trajetória do PL 4685/2012. Mercado de Trabalho, v. 21, n. 58, p. 91-100, 2015. Disponível em http://repositorio.ipea.gov.br/bitstream/11058/4231/9/bmt_58_economia_busca.pdf. Acesso em 05 de fevereiro de 2018.

SINGER, P. Economia Solidária versus Economia Capitalista. Sociedade e Estado, v. 6, n. 1-2, p. 100-112, 2001. Disponível em http://www.scielo.br/pdf/se/v16n1-2/v16n1-2a05.pdf. Acesso em 04 de abril de 2017.

SPINK, P.K. Micro cadeias produtivas e a nanoeconomia: repensando o trabalho decente. Cadernos de Psicologia Social e do Trabalho, v. 12, n. 2, p. 227-241, 2009. Disponível em 
http://pepsic.bvsalud.org/scielo.php?script=sci_arttext\&pid=S1516-37172009000200008. Acesso em 22 de maio de 2017.

VISEU, F. Contribuição da Sociologia da Dádiva aos estudos dobre as Organizações Substantivas. Organização e Sociedade, v. 16, n. 50, p. 409-427. (2009). Disponível em http://www.scielo.br/pdf/osoc/v16n50/01.pdf. Acesso em 31/03/2017.

WARREN, Ilse Scherer (2006) Das mobilizações às redes de movimento sociais. Revista Sociedade e Estado, v. 21, n. 1, p. 109-130. Disponível em http://www.scielo.br/pdf/se/v21n1/v21n1a07.pdf. Acessado em 04/04/2017. 